Supplement of

\title{
Last Glacial Maximum to Holocene paleoceanography of the northwestern Ross Sea inferred from sediment core geochemistry and micropaleontology at Hallett Ridge
}

Romana Melis et al.

Correspondence to: Lucilla Capotondi (lucilla.capotondi@bo.ismar.cnr.it)

The copyright of individual parts of the supplement might differ from the CC BY 4.0 License. 


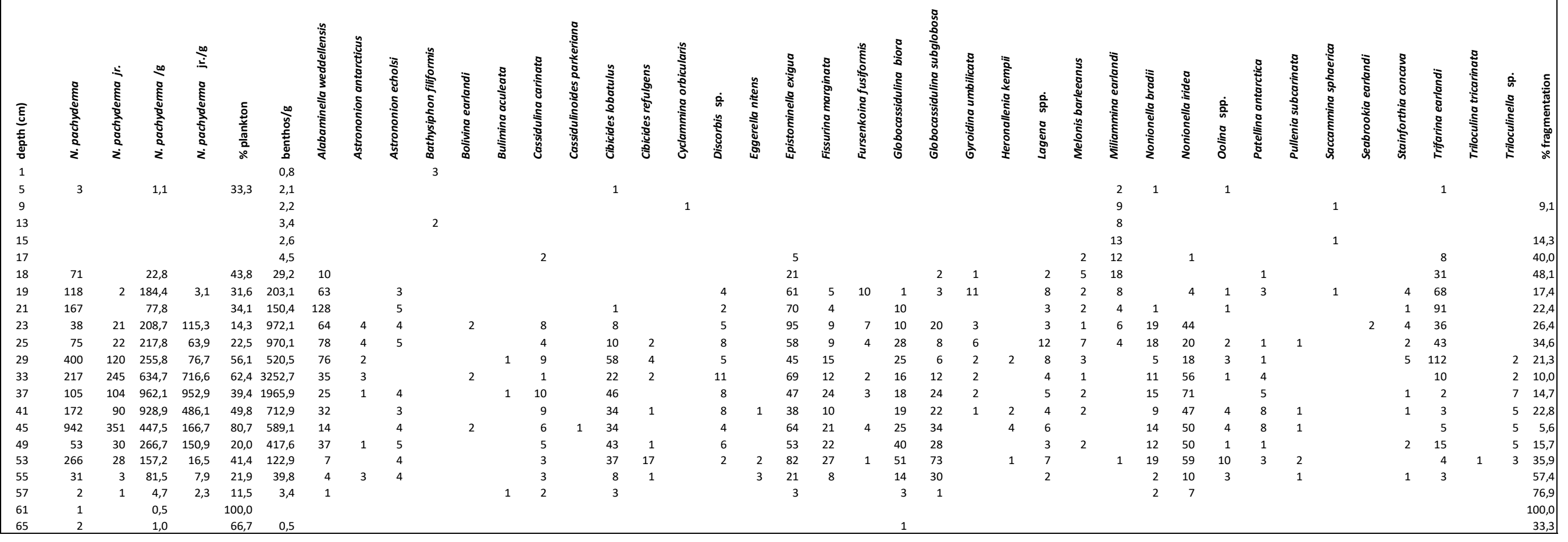


Table S 2

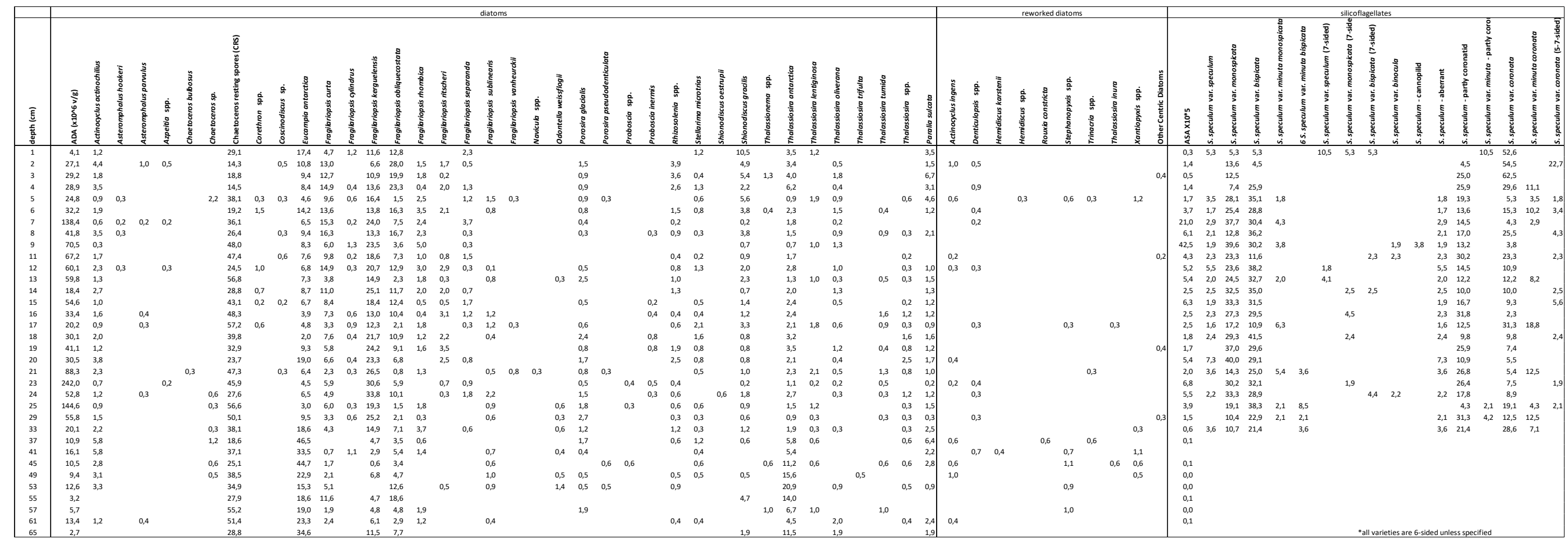

